\title{
Heidegger à conversa com Heidegger
}

Os organizadores,

Emanuele Mariani

Irene Borges-Duarte

Via viatores quaerit

Inteiramente dedicado ao pensamento heideggeriano, o presente número de Phainomenon leva ao amadurecimento os frutos do que, no início, foi um encontro entre estudiosos, reconhecidos ou na fase inicial da carreira, ligados por afiliação institucional ou afinidade eletiva à língua e cultura portuguesas. Um encontro que teve lugar em Évora em 2019, com base numa colaboração entre a Universidade de Évora e a Universidade de Lisboa, sob o título de "II Jornadas Heideggerianas", e que pretendia dar continuidade às primeiras "Jornadas Heideggerianas de Évora" organizadas em 2013, com o objectivo de estabelecer um diálogo entre aqueles que, em Portugal, se dedicam total ou parcialmente ao estudo do pensamento de Martin Heidegger e à tradução da sua obra em língua portuguesa. Mais do que o título, porém, é o subtítulo do encontro de 2019 que nos permite compreender o lema que une todas as contribuições aqui apresentadas: "Heidegger à conversa com Heidegger".

A auto-interpretação de Heidegger do seu próprio caminho oferece, de facto, um critério de trabalho essencial para a análise histórico-conceptual dos momentos constituintes desta grande visão filosófica cuja complexidade levanta, a um nível hermenêutico, e num sentido muito específico, o problema da unidade da obra - a obra heideggeriana, entendida à imagem de um "caminho" como, aliás, o próprio Heidegger explica claramente, construída passo a passo, através de trilhos, veredas, desvios e saltos. Não menos essencial, 
por outro lado, é o questionamento a que Heidegger tem constantemente submetido, a um nível teorético, os resultados ou, melhor, as etapas alcançadas ao longo da sua trajectória. Este questionamento coincide, no essencial, com o gesto de uma reflexão meditativa e problematizante, ou seja, filosófica, com uma espécie de diálogo interior destinado a captar as motivações internas, as hesitações e, não menos importante, as possibilidades inexploradas da "coisa mesma”, para dizê-lo em termos heideggerianos, que o pensamento é chamado a pensar.

A este respeito vale a pena citar as palavras dirigidas a Elisabeth Blochmann numa carta de 18 de Novembro de 1932, na qual Heidegger não hesita em afirmar esta exigência reflexiva que se impõe antes de qualquer confronto externo com outras figuras da filosofia, e que aparece com ainda mais força se considerarmos que, nessa altura, a comunidade académica esperava em vão - que a segunda parte de Ser e Tempo fosse publicada e que, desde 1931, tanto Husserl como Cassirer tinham divulgados as suas críticas:

Para já estou a ler os meus manuscritos, quero dizer, a ler-me a mim mesmo. E devo dizer que, tanto no positivo como no negativo, está a ser-me muito mais frutífero que outras leituras, que nem me apetecem nem tenho ocasião de fazer. (Briefwechsel, 53)

Hoje, confirmando o que tornou-se evidente desde 1989 com a publicação dos Beiträge (GA 65), a atenção topológica de Heidegger para a progressão da sua própria investigação assume, se possível, ainda maior importância em virtude das mais recentes publicações da Gesamtausgabe. Basta pensar nos volumes 73 (1 e 2), 76 e, sobretudo, 82, e também em grande parte do conteúdo dos Cadernos negros, embora neste último caso a interpretação tenha sofrido, pelo menos até agora, de uma certa unilateralidade. As contribuições aqui recolhidas inscrevem-se, cada uma à sua maneira, nesta linha hermenêutica, escolhendo como tema de investigação aspectos tópicos do pensamento heideggeriano como a afectividade, a alteridade, a espacialidade, as disposições, etc., numa tentativa de lançar luz, directa ou indirectamente, sobre o sentido geral da obra pelo filtro das duas imagens-guia, paradigmáticas e relacionadas, da "conversa" e do "caminho". 
Trata-se de contribuições autónomas que em parte dialogam entre si, e que podemos resumir nos seguintes termos através de um rápido olhar sinóptico. Irene Borges-Duarte, com $O$ caminho e a conversa, define e confirma o tema da colecção, retraçando as principais etapas da obra heideggeriana cujos momentos principais são relidos em função do gesto autointerpretativo do próprio Heidegger. Entre a temporalidade como horizonte transcendental ao qual Heidegger, em 1927, confere o sentido da Seinsfrage e o Ereignis que, a partir dos anos 30, abre a possibilidade de uma outra articulação da relação dinâmica entre o ser e o tempo, o foco está particularmente na transição que Heidegger realiza no final dos anos 20 através do confronto com Kant, em que se assiste a elaboração de uma metafísica do Dasein que servirá de "ponte" para o "novo caminho" com que as páginas dos Beiträge se medem.

Bernard Sylla, com A espacialidade existencial em Ser e Tempo, baseando-se numa crítica de Sloterdijk a Heidegger, reconstitui as revisões de Heidegger sobre a própria concepção do espaço em Ser e Tempo. O objectivo é realçar uma dimensão da espacialidade que a análise existencial teria permitido vislumbrar, sem, contudo, explorar plenamente as suas consequências sistemáticas: uma espacialidade intersubjetivamente reconfigurada em função do Mitdasein, do qual resultariam novas articulações possíveis do "espaço" existencialmente compreendido. A originalidade desta proposta é acompanhada por uma análise da revisão a que Heidegger, em diálogo consigo próprio, submeterá a primazia da temporalidade sobre a espacialidade em virtude do Ereignis enquanto origem comum a ambas.

$\mathrm{O}$ artigo de Chiara Pasqualin, Existe um ante-predicativo pático?, faz uma analise original do conceito de ante-predicativo, realizando um aprofundamento alternativo aos resultados da literatura secundária que frequentemente, e talvez demasiado rapidamente, identificam o antepredicativo com o pré-teorético. Segundo Pasqualin, o ante-predicativo pático deve ser interpretado como preliminar à articulação hermenêutica do In-derWelt-sein, colocando-se em relação directa com a Befindlichkeit enquanto abertura original do Dasein prévia, se não num sentido genético, pelo menos num sentido ontológico, ao Verstehen. Daqui surge a possibilidade de afirmar a primazia da dimensão pática como pré-significativa e, consequentemente, 
pré-hermenêutica, cujos efeitos sistemáticos farão impacto na figura do "grande silêncio" que Heidegger enfrenta na década de 1930.

Partindo do $\$ 42$ de Ser e Tempo em que Heidegger, como sabemos, evoca a fábula de Higino sobre a origem do homem a partir do húmus pela obra da Cura, o artigo de Luís Gabriel Provinciatto, $O$ (con)texto de uma nota: Heidegger e os aspectos fáctico e pré-ontológico do cuidado, visa analisar as diferentes matrizes conceptuais que encontramos na base da formulação do fenómeno da Sorge, e que Heidegger explicita numa nota de rodapé: a antropologia agostiniana e a ontologia aristotélica. A inflexão ditada pela análise existencial permitiria assim apreciar o carácter factual e, ao mesmo tempo, ontológico do cuidado enquanto estrutura fundamental e unitária do ser do Dasein, ressaltando a sua dimensão transcendental.

Centrando-se no conceito de "disposição", Helder Telo em Passividade e atividade na descrição heideggeriana das disposições prossegue um exame textual de alguns dos lugares mais significativos da obra heideggeriana onde é possível perceber a originalidade de uma compreensão especifica da dimensão emocional-afectiva do homem capaz de desafiar a dicotomia entre passividade e actividade que emerge das propostas mais recentes do debate actual e, ao mesmo tempo, de complementar os resultados, basicamente apóreticos, a que o legado da história da filosofia conduz. Objecto de descrição e conceito metodológico da análise existencial, o tema das "disposições" perderia, entre os anos 20 e 30, a função transcendental que Heidegger lhe atribuía inicialmente. Nisto, Telo aproveita a oportunidade para multiplicar os modelos de compreensão do conceito de "disposição", propondo, de um ponto de vista hermenêutico, um parâmetro adicional para medir a progressão interna do caminho heideggeriano.

A partir do $\$ 29$ de Ser e Tempo, centrando-se na figura da Befindlichkeit, Maria Adele Pacheco propõe em Alteridade e afetividade em diálogo com Ser e Tempo uma leitura ampla e articulada que, atravessando, ainda que rapidamente, a quase totalidade do pensamento heideggeriano, visa atestar a presença em Heidegger de um pensamento da alteridade. Para além de Ser e do Tempo, a análise concentra-se nos Beiträge dos anos 30, na leitura de Hölderlin e, ao mesmo tempo, da tragédia grega, para se deter no problema da técnica e, finalmente, na quadratura ontológica do Geviert. A relação entre Befindlichkeit, Stimmungen e solipsismo serve neste sentido como um fio 
condutor para ilustrar como, com referência ao problema da alteridade, a ausência de uma ética explicitamente formulada por Heidegger não significa de forma alguma a sua impossibilidade.

Em Heidegger e a superação da sua compreensão transcendental de mundo, Dominique Mortiaux apresenta uma leitura global que, partindo de Ser e Tempo, encontra uma possível realização da sua incompletude intrínseca na questão da técnica e na superação do niilismo. Da compreensão do ser baseado na compreensão transcendental do mundo, o cerne da análise deslocase para a compreensão do ser como história. O foco é, em última análise, a ligação entre falar e ouvir à luz do diálogo com a poesia, que serve como chave para aceder ao pensamento do ser.

Em conclusão, gostaríamos de dizer uma palavra sobre a escolha de manter a língua portuguesa para a publicação desta coleção: uma escolha que, naturalmente, não é ditada por razões de identidade cultural atribuíveis a uma alegada especificidade dos estudos heideggerianos em Portugal, nem, muito menos, e pelo contrário, deve ser entendida como o resultado de uma contingência. Se o diálogo, platonicamente ou heideggericamente compreendido, é um momento essencial do fazer filosofia, a filosofia enquanto symphilosophein não pode de forma alguma abstrair-se do sentido de uma comunidade, real ou virtual, feita de ideias ou de pessoas, sob pena da sua desvitalização. Desejámos, portanto, na medida do possível, preservar o carácter vivo do encontro de que a língua é parte, e que nos permitiu "caminhar juntos", mesmo que apenas por uma curta distância, tornando a viagem uma oportunidade de conversa consigo mesmo e uns com os outros. Gostamos assim de pensar, como companheiros de viagem, que é a via que procura os viajantes. 